\title{
LA MIRADA DEL OTRO. BREVE AUTOFICCIÓN INTELECTUAL
}

\section{The look of the other. Short intelectual autofiction}

\author{
Felipe Arocena* \\ * Universidad de la República (Uruguay) \\ farocena@fcs.edu.uy
}

Palabras clave

Autobiografía

Sociología

latinoamericana

Identidad

Keywords

Autobiography

Latinoamerican

sociology

Identity

\section{$\underline{\text { Resumen }}$}

Esta breve autobiografía o autoficción intelectual trata de idas y vueltas, de salidas y retornos, y de algunas de las influencias que percibo fueron significativas en mi vida, en mi formación profesional y en mi mirada sobre América Latina. Desde diferentes perspectivas reflexionaré también acerca de cómo esa experiencia académica y vital en Europa y Estados Unidos modeló mi identidad de sociólogo. Ese fue el desafío que me ofreció el editor de la revista y fue el espíritu con el que escribí este texto.

\section{Abstract}

This short intellectual autobiography, or autofiction deals with departures and returns, goings and comebacks, and with some of the significant influences on my life, my professional career and my look on Latin America. From different perspectives I will also examine how that personal and academic experience in Europe and the Unites States of America shaped my sociological identity. This was the challenge offered by the editor of the journal and was the spirit with which I wrote the following text.

Arocena, F., 2015, "La mirada del otro. Breve autoficción intelectual”, en Papeles del CEIC, vol. 2015/1, no 120, CEIC (Centro de Estudios sobre la Identidad Colectiva), Universidad del País Vasco, http://dx.doi.org/10.1387/pceic.13298

At every single moment of one's life one is what one has been no less than what one is going to be. Art is a symbol, because man is a symbol. (Oscar Wilde, De profundis)

\section{INTRODUCCIÓN}

Borges se preguntaba si de no haber viajado a Europa entre los quince y los veintidós años de edad hubiera sido capaz de percibir con la misma intensidad el encanto peculiar de la ciudad de Buenos Aires, a la que prácticamente le inventó su periferia tanguera entre versos y cuentos 
compadritos. El peruano José Carlos Mariátegui viajó a los veintiséis años a Italia y pegó la vuelta tres años más tarde trayéndose consigo la linterna futurista con la que iluminó la metafísica de las tradiciones precolombinas plasmada en la vida comunitaria de los ayllus quechuas. Y Oswald de Andrade, ese brasileño antropófago, descubrió su propia tierra, según interpretación de uno de sus contemporáneos, desde el ombligo del mundo parisino de la Place Clichy y acuñó la célebre frase: tupi or not tupí that is the question (Jorge Schwartz, 1991). Es bastante evidente la razón por la cual juntar en este párrafo inicial a estos escritores sudamericanos. Los tres vivieron en el norte rico del mundo y esa trayectoria de vida fue determinante para mirar con nuevos ojos su lugar de pertenencia. Los tres pasaron por la experiencia fenomenológica que el sociólogo busca y crea adrede, pusieron entre paréntesis los mundos familiares desde los que partieron en el mismo movimiento en que se encontraron con el otro. Experimentaron el proceso dialéctico y simultáneo de hacer de lo extraño algo familiar al mismo tiempo que lo familiar se vuelve extraño y por ende visible (Roy Wagner, 1981). Esta es la raíz de lo que Wright Mills (1959) describió como la imaginación sociológica, fuente indispensable para crear otros mundos posibles.

Yo quería ser arquitecto. Como lo había sido mi destacado abuelo materno que entre sus cientos de obras y muchas iglesias católicas había proyectado la de Las Carmelitas en la calle Irigoytía, apenas a dos cuadras de la casa donde viví mi infancia en el barrio montevideano del Prado. La sombra de mi abuelo era densa y la profesión de arquitecto, la marca de identidad familiar, tanto que siete de mis parientes directos viven de ella o de especialidades afines. Podríamos haber sido incluso ocho. Durante la dictadura uruguaya fue en el único período en el que la Universidad de la República estableció un examen de ingreso para todas las carreras. La medida duró dos años consecutivos y me tocó rendir la prueba de admisión en 1981. Mi nombre apareció por primera vez en un diario integrando la lista de los aprobados de la Facultad de Arquitectura. Con el salvoconducto asegurado para poder convertirme en un futuro inventor de espacios tan bueno como mi abuelo, decidí tomarme un año sabático. Había ahorrado dinero suficiente trabajando de mozo toda la temporada de verano en un restaurante del balneario José Ignacio y en marzo me subí a un avión de la compañía Lufthansa. El segundo de mis hermanos hacía un año que se había ido enamorado a París $y$, sin avisarle nada, le toqué una tarde de domingo el timbre de su apartamento de la Rue Sedaine. 
Nadie me contestó y la sorpresa me costó cara, pues tuve que esperarlo medio día sentado en el corredor oscuro del edificio, pero bien valió la pena. Era marzo de 1982 y yo tenía las ilusiones de los diecinueve años recién cumplidos.

\section{2. ¿QUÉ HACÍAN TANTOS LATINOAMERICANOS EN PARÍS?}

Conversaban acaloradamente una nicaragüense afín al Frente Sandinista de Liberación Nacional, un hijo de desaparecidos uruguayo, un afiliado al Partido Comunista argentino, un francés socialista de traje a rayitas finas azules y blancas, bigote espeso y semblanza quijotesca, un integrante del Movimiento de Izquierda Revolucionaria chileno y varios uruguayos y argentinos más. El tema era la guerra de las Malvinas y generaba discusiones intensas. El comunista argumentaba que había que defender incondicionalmente al país frente a la agresión británica, a pesar de que estuviera en el poder la junta militar más sangrienta de la historia. La crítica a la dictadura, la denuncia por los treinta mil desaparecidos y la violación sistemática de los derechos humanos, la coerción de los medios de información y de las libertades individuales, pasaban a segundo plano frente a la agresión externa de una potencia como Inglaterra. El francés se oponía tajantemente a esta manera de ver las cosas y afirmaba que los militares habian fabricado esta guerra para lograr adhesión a su gobierno y tomaban de rehén a la población; si ganaban la impunidad se perpetuaría bastante tiempo más, pero si perdian se derrumbarian inmediatamente. y un grupo de varios no sabian bien qué posición tomar, dudaban entre doblegarse ante la prepotencia colonial británica para debilitar a los militares argentinos y el sentimiento de rabia por no encontrar una solución apropiada a la paradoja que se había planteado. Cuestionar a los ingleses era animar a los dictadores, apoyar a la Argentina implicaba la posibilidad de renovar nada menos que a la dictadura. Yo escuchaba perplejo.

El exilio latinoamericano en toda Europa fue muy activo y en la Francia socialista de Mitterrand explotaba. Alli operaban integrantes de los revolucionarios sandinistas nicaragüenses, de los farabundistas salvadoreños, de las resistencias a las dictaduras uruguaya, brasileña y chilena. Todavía México y Cuba, con sus gobiernos revolucionarios eran los espacios liberados a los que nadie criticaba, los únicos que no habian sucumbido a las maniobras de los Estados Unidos pergeñando golpes de estado y financiando a los gorilas como estrategia para frenar la avanzada 
comunista en el sur del continente. La URSS, ya ampliamente denostada por los europeos espantados ante el totalitarismo y el terror estalinista todavía mantenía, entre los latinoamericanos, un espacio ambiguo de duda. La política lo dominaba todo, si había un espectáculo musical el objetivo principal era la denuncia o la recaudación de fondos, si un escritor daba una conferencia la prioridad era su crítica a los gobiernos dictatoriales, si se estrenaba una película debía tener un mensaje de denuncia. Así que yo pasé de la noche a la mañana de un universo en el que la política era inexistente a otro en el que era excluyente. Mi choque cultural fue bifronte y un poco contradictorio, desperté abruptamente a la política desde un sueño montevideano y una posición ciertamente confortable y al mismo tiempo me deslumbré con las maravillas que ofrecía la cultura parisina: era la época del movimiento punk, las calles de la ciudad reverberaban con la diversidad de estilos, con los inmigrantes que llegaban desde África y con los turistas que atiborraban los espacios públicos. Solamente caminar por las callejuelas y perderme me extasiaba. Años más tarde Walter Benjamin (2006) me explicó lo que yo sentía.

Hasta ese momento mi relación con la política uruguaya había sido vivencial y no ideológica. Los primeros recuerdos políticos son en mi casa de la infancia. Muchas noches mi padre paralizaba el tiempo doméstico cuando se sentaba en un sillón de cuero marrón claro, encendía un cigarrillo Republicana sin filtro, se servía un vaso de whisky Ancap (él decía que era el más puro, pero en realidad era el más barato) encendía una radio de plástico azul Philips y todos quedábamos hipnotizados cuando surgía la voz de Wilson Ferreira Aldunate. Wilson tenía audiciones radiales nocturnas y aunque no recuerdo su periodicidad, debieron ser muchas. No tengo ni idea los temas que tocaba, pero la atención de mi padre era total y eso era signo de que algo muy importante estaría diciendo. El magnetismo de su voz y el miedo a que mi padre nos mandara callar, conseguían asegurar un rato casi sagrado en el seno de la familia. Seguramente esto ocurrió en la campaña de las elecciones nacionales de 1971 o en algunas de las interpelaciones con las que volteó ministros. De esa campaña recuerdo los cánticos provocativos contra el Frente Amplio: "Seregni rucucú, alcahuete de Moscú" y la respuesta: "Wilson banana, mirá que caravana". Ganaron los colorados otra vez y el propio Wilson decía del presidente electo: "vasco inteligente es Unamuno, vasco burro es Bordaberry". Un segundo evento que mi memoria grabó también ocurrió de noche, fue cuando en el medio de una cena escuchamos una explosión de vidrios 
rotos en el frente de nuestra casa. Corrimos a ver qué había pasado y nos enfrentamos a una masa de alquitrán y vidrios sobre la escalera del frente. Nunca supimos cuál fue la causa de la agresión. Nuestra casa de la calle Buschental (lindera con la del actual Presidente de Uruguay de Tabaré Vázquez que en esos años no vivía allí) puede que haya sido confundida con la de otra familia que alguno de los grupos de izquierda o el propio MLN deseaba molestar. O puede simplemente que la agresión haya sido un acto genérico contra un barrio tal vez considerado burgués, y por lo tanto todos los habitantes de sus casas, generalmente espaciosas, "enemigos del pueblo". Ni mi padre ni mi madre tuvieron militancia política activa, más allá de su wilsonismo y las raíces blancas de mi familia paterna. Estos hechos fueron antes de la dictadura y cuando se dio el golpe de estado en junio de 1973 la política se silenció en mi familia y apenas se hablaba de un primo hermano preso y otro desaparecido y del exilio de Ferreira Aldunate, o de la enemistad de mi padre con su hermano causada, nos decian, "por discrepancias políticas". Ya en dictadura una noche mi padre exigió que todos los libros que tenía mi hermana mayor en su cuarto fuesen quemados. Las Actas tupamaras, los folletos de izquierda, y el resto de los ejemplares de "literatura de izquierda" que ella había juntado fueron a parar uno por uno a la estufa de leña asegurándonos que todas las páginas se desintegraran. Yo senti el miedo que sintieron mis padres y mi hermana, pero no entendía el origen. La política reapareció fugazmente, aunque con fuerza, en el plebiscito de 1980 y todos en mi casa menos yo, que era menor, votaron en contra. Bueno, mi padre tampoco votó porque murió en el verano de ese mismo año. Estas vivencias, que llamo ahora "experiencias políticas", porque no sé qué otro nombre darles puesto que yo no era un ser en absoluto politizado, empezaron a demandarme más atención tras el contacto con ese mundo de resistencia europeo. El embrión del sociólogo se gestó en ese momento y no hubo aborto. Mi estado de ánimo más frecuente en esos años nuevos que comenzaban podría resumirse con las palabras perplejidad, sorpresa, curiosidad enfermiza y transformación personal.

\section{3. ¿CÓMO EXPLICAR EL FRACASO? LA FORMACIÓN EN PLENA DICTADURA}

Aproveché mi año sabático y recorrí un espacio extenso de Europa, parte significativa de ese tiempo lo pasé trabajando para poder seguir avanzando: fui empaquetador para un comercio de argentinos que 
importaba artesanía de México en París, fui changador para un restaurador de muebles, y durante cuatro meses me contrataron de marinero en un velero cuyo dueño era un griego capitán de la marina mercante llamado Takis. El barco también tenía nombre, era el Blue Trout y lo llevamos desde el puerto de El Pireo en Atenas hasta La Rochelle en Francia. No hace falta aclarar que esos cuatro meses se cuentan entre los más maravillosos de mi vida, pero eso no es material para este texto aunque el embrión también se hizo resistente y creció suficientemente con esa experiencia de vida. En este caso fue Joseph Conrad quien me lo explicó con bastante posterioridad (Joseph Conrad, 1989).

Bien podría decirse que ése fue mi primer regreso. Había pasado un año en el norte y volvía distinto, muy cambiado creía yo entonces, aunque ahora a la distancia me pregunto cuánto realmente. ¿Cuánto queda de uno a pesar de los cambios vitales? ¿Cuánto podemos transformarnos sin dejar de reconocernos como nosotros mismos? ¿Es acertado el epígrafe inicial, es cierto que uno es en todo momento su pasado tanto como lo que construirá en su futuro? ¿Es cierto que además uno y otro -pasado y futuro- dependen de las interpretaciones con que los decodifiquemos, como un símbolo que puede adquirir múltiples significados? ¿Se aplica esto a la identidad intelectual tanto como a la de la persona?

En Montevideo la licenciatura de sociología había sido cerrada por la dictadura y en 1983 había tres lugares que me recomendaron para estudiar ciencias sociales. Existía la Licenciatura de Antropología en la Facultad de Humanidades de la Universidad de la República, se ofrecían algunos cursos sobre sociología en el Instituto de Ciencias Sociales de la Facultad de Derecho también de la misma universidad pública, y funcionaba el Grado en sociología del desarrollo del Centro Latinoamericano de Economía Humana-CLAEH, un instituto privado. Ingresé a los tres al mismo tiempo.

La antropología que se ofrecía en la Facultad de Humanidades estaba completamente dominada por la figura autoritaria y mediocre de Olaf Blixen. Su principal enemigo intelectual era Claude Lévi-Strauss, de cuyo estructuralismo no rescataba nada porque lo consideraba una teoría materialista del ser humano desprovista de toda sensibilidad por el fenómeno religioso y cultural. Para entrar al edificio de la Facultad de Humanidades, había que entregar la cédula de identidad en una mesa de entrada con tres funcionarios que controlaban el movimiento. La Universidad de la República había sido intervenida por la dictadura y el movimiento estudiantil comenzaba a adquirir protagonismo central en la 
resistencia interna a través de la ASCEEP, organización que sustituyó a la histórica FEUU, prohibida inmediatamente al golpe. Cursé dos años de antropología que, a pesar de Blixen, me abrieron un mundo intelectual nuevo que aún no se cerró. Fue allí que leí por primera vez fragmentos de Franz Boas, Ruth Benedict, Bronislaw Malinowski, Edmund Husserl, LéviStrauss; aprendí sobre totemismo, sobre métodos de datación, sobre las aventuras de los etnógrafos internándose en universos distantes y distintos a los occidentales y así creció significativamente mi imaginación sociológica. Además la militancia estudiantil con sus asambleas, sus convocatorias públicas y sus debates, creaba una convicción de que podiamos incidir en cambiar la situación política del país. Fue el momento de asumir riesgos y la mayoría lo hicimos, aunque algunos lo pagaron muy caro. Allí cursé dos años.

El Instituto de Sociología de la Facultad de Derecho era un espacio donde la dictadura intentó enseñar sociología de derecha. Alli daba la materia de historia de las ideas un señor de apellido Varela Sienra, que se ufanaba de haber sido él mismo quien firmara el decreto de inhabilitación para José Pedro Barrán, el mayor historiador del país de los últimos cincuenta años. Alli estuve apenas unos meses y fue lo primero que descarté.

A diferencia de las instituciones anteriores, el CLAEH era una isla intelectual. Alli sorpresivamente los profesores eran todos opositores y muchos habian trabajado en la propia Udelar antes de la intervención. No había censura, se leían todos los clásicos de la sociología y se discutían las versiones latinoamericanas basados en ellos, se analizaban las teorías de la revolución, se estudiaban los movimientos sociales, se presentaban las doctrinas anarquista, comunista y socialista en un mismo nivel de profundidad que el liberalismo, la social democracia o el darwinismo social. y además se enseñaba una metodología muy respetable que incluía estadística, diseño de investigación, análisis de datos, técnicas de entrevistas. Ese era un espacio de avanzada que se mantenía con una fuerte financiación desde el exterior y allí hice mi primera formación sistemática en sociología. No obstante, siempre recuerdo a un gran profesor que comenzó su curso de epistemología de las ciencias sociales con la siguiente afirmación: "si no aceptamos que existe un mundo exterior, que éste tiene un orden y que ese orden es cognoscible, no podemos hacer sociología o ciencias sociales". Su perspectiva era el positivismo de Richard S. Rudner y su libro La filosofía de la ciencia social 
(1973), y a pesar de ello él era quien dominaba mejor algunos de los núcleos centrales de la teoría sociológica en Uruguay.

Terminé el Grado del CLAEH y me seleccionaron con una beca para formar parte del Curso de Formación de Investigadores en Ciencias Sociales del Centro de Investigaciones y Estudios sobre el Uruguay-CIESU. Ese fue el sueño realizado: la dictadura había caído en 1985 y en el mismo año comenzaron a pagarme para perfeccionar mis estudios en lo que más me gustaba que era la sociología. Uno de mis intereses centrales que me acompaña hasta el presente se delineó con claridad en ese momento. Quería entender un poco mejor lo que había experimentado en aquel contacto inicial con los exilados latinoamericanos. ¿Por qué las sociedades latinoamericanas habían caído tan bajo? ¿Cómo se había llegado a ese nivel de violencia social y política? Mi primera tesis de maestría fue justamente un análisis del surgimiento de la violencia política en el Uruguay de los años sesenta. Quería acercarme a entender lo que en ese entonces para mí era algo tan claro como el agua: el rotundo fracaso latinoamericano y de mi propio país.

Hasta ese período había dos macro teorias que intentaban explicar el naufragio. La primera era la Teoría de la modernización, cuyo exponente local más visible era el ítalo argentino Gino Germani. En su Sociología de la modernización: Estudios teóricos, metodológicos y aplicados a América Latina, publicado en el año 1969, nos traducía las teorías europeas, a las que adaptaron a su vez los estadounidenses, sobre el tránsito de las sociedades atrasadas a las modernas. El esquema era bastante sencillo: así como las sociedades europeas habían pasado del feudalismo al liberalismo en su base política, del mercantilismo al capitalismo en su sistema económico, de la comuna hacia el individualismo en su organización social, y de una cosmovisión religiosa a una secular en su legitimación cultural, las sociedades latinoamericanas seguirían esa evolución. Este tránsito entre el atraso de los países latinoamericanos hacia la modernidad se llamaba modernización, la modernidad era el estadio de los países europeos y era el modelo excluyente; era el futuro, que, como una fuerza de gravedad irresistible, nos atraía. La solución teórica para explicar nuestro fracaso radicaba en que ese movimiento entre el atraso y la modernidad había comenzado mucho más tarde en América Latina que en el mundo llamado moderno. A esta espina dorsal de la teoría, luego se la complementaba con un sinfín de particularidades locales y regionales incluyendo distintas historicidades, configuraciones demográficas diversas, recursos 
económicos variados, y antecedentes coloniales heterogéneos que acercaban la gran explicación, o el macro relato, a las especificidades nacionales. A mí me parecía plausible esta explicación en los años ochenta.

La otra macro teoría que explicaba el fracaso latinoamericano era la Teoría de la dependencia. A pesar de todas sus variaciones siempre me interesó más el producto original que sus adaptaciones. El libro Dependencia y desarrollo en América Latina, de Fernando Henrique Cardoso y Enzo Faletto fue publicado el mismo año que el de Germani, también en 1969. Desde esta perspectiva se cuestionaba la fuerza de gravedad que impulsaba el tránsito modernizador. Ese trayecto entre el atraso y la modernidad estaba siendo interrumpido conscientemente por los países que ya se habian modernizado porque vivían de frenarlo. América Latina proveía los recursos materiales baratos y la mano de obra a bajo costo, imprescindibles para mantener funcionando el círculo de producción de bienes de consumo con alto valor agregado que los países ricos le vendían de vuelta. Había que romper ese círculo perverso, esa dependencia, para que efectivamente ocurriera el tránsito del atraso a la modernidad. Esa era la clave diferente y esa clave era política porque se debía modificar la estructura de poder. Para esto se precisaba una movilización social que confrontara el poder económico internacional y a sus brazos locales que eran las burguesías cipayas nacionales. A mí también esta explicación me parecía plausible.

Si bien durante varias décadas dependentistas y modernizadores se disputaron certezas opuestas nunca me parecieron contradictorias. Si soslayamos lo que llamé la clave política para destrabar la modernización, la interpretación de Cardozo y Faletto era la misma que la de los modernizadores. Y lo era porque la sociología entera se había gestado bajo esos postulados y los sociólogos latinoamericanos tenían formateada la cabeza con sus clásicos europeos: con el pensamiento de Weber, Durkheim, Marx, de Tocqueville, Simmel. Ellos y la disciplina que inventaron tuvieron el propósito común de entender esa brutal metamorfosis social entre el antiguo régimen y la modernidad, que a veces se daba a través de la revolución política, como en Francia, pero no siempre de la misma manera (Robert Nisbet, 1977).

Cometí una herejía. Junté las dos teorías en un sólo trabajo y escribí mi tesis de maestría para FLACSO-CIESU, titulada "Violencia política en el Uruguay de los sesenta. El caso de los Tupamaros"; fue mi primera publicación. En ese período también ingresé a la Universidad de la 
República como Profesor Ayudante y me encargaba de algunos prácticos del curso introductorio a la sociología de la Facultad de Derecho.

Corría la segunda mitad de la década de los ochenta y en ese período, como para la enorme mayoría de los uruguayos, primero predominó un sentimiento de euforia por la transición democrática y la victoria contra los militares, que cedió demasiado rápido al enojo, al desencanto de la real politik, al pesimismo ante tantas inercias y a cierto mal humor generalizado. Quería continuar mi formación y eso no era posible dentro del país, así que como la mayoria de mis colegas también me fui.

\section{4. ¿QUÉ HACÍAN TANTOS LATINOAMERICANOS EN RÍO DE JANEIRO?}

El gobierno brasileño había diseñado una estrategia internacional para vincularse con sus países vecinos otorgando miles de becas de posgrado para maestrías y doctorados. De esta manera lograba que muchos de los científicos, artistas e intelectuales mejor preparados de cada país sudamericano viviesen varios años en Brasil, aprendieran el portugués y la historia brasileña, y al regresar fuesen poleas de transmisión para que Brasil aumentase su influencia regional. Fue y sigue siendo una estrategia extraordinariamente eficiente porque son miles los sudamericanos que maduraron su formación en Brasil. Yo uno de ellos.

En el Instituto Universitário de Pesquisas de Río de Janeiro-IUPERJ cursé primero una maestría (en realidad fue mi segunda maestría) y luego un doctorado. Si sumamos ambos períodos debo reconocer que CAPES, institución del Ministerio de Educación brasileño, financió ocho años de mi formación y de mi vida.

Toda autobiografía es una selección arbitraria de eventos, personas y estados de ánimo y por eso más recientemente se prefiere hablar de autoficción (Kelley Duarte, 2014). En verdad inventamos una narración biográfica cuya cercanía con la realidad siempre es remota. Funes, el memorioso, nos mostró elocuentemente cómo el objetivismo del realista positivista es una tarea no solamente imposible sino indeseable porque su mero intento nos postraría en una cama. Y los sociólogos, así como los antropólogos, hacemos interpretaciones de interpretaciones, que hemos denominado el proceso de la "doble hermenéutica". Y eso es lo que estoy yo haciendo en este momento: interpreto interpretaciones realizadas por mí hace años. Este cambio epistemológico, que además es ontológico, puesto que la propia sociedad se constituye de esas interpretaciones, fue 
tal vez la mayor revolución mental en mi formación (jrecordemos que me había iniciado en el positivismo de Rudner!). Esto lo adquirí en las discusiones teóricas de mi educación en Brasil, donde había una actualización sorprendente de lo que se producía en Europa. Una segunda revolución mental que condicionó todo mi futuro trabajo fueron las lecturas diversas sobre la crítica de la modernidad que plasmé en mi tesis de maestría: La modernidad y su desencanto. Modernos, posmodernos y neoconservadores en el discurso sociológico. Analicé allí en detalle la teoría de la racionalización de Max Weber, pasando por la dialéctica de la ilustración de Adorno y Horkheimer, hasta la Teoría de la Acción Comunicativa de Habermas; estudié las crítica de Daniel Bell sobre las contradicciones culturales del capitalismo y los descontentos con la secularización analizados por Peter Berger; y me sedujeron los demoledores torpedos de Baudrillard contra la simulación junto a los incisivos argumentos de Lyotard desmontando las certezas de la filosofía de la historia. Lo que las teorías de la modernización y de la dependencia habian interpretado como el mundo moderno y se planteaban como meta a alcanzar, dejó de serlo para mí. Por lo menos el fracaso latinoamericano no era el único, había un relato también del naufragio de los sueños de la modernidad, de los delirios del racismo, del ser humano devenido en insecto en la cultura de masas y del sinsentido del mundo desencantado.

En paralelo con esas dos transformaciones que marcaron mi posición hasta el presente, ocurrió una tercera que estuvo asociada con el impacto de los latinoamericanistas. Brasil era y es uno de los países más atractivos para los cientistas sociales del norte que optaban por mirar profesionalmente la cultura y las sociedades al sur del Río Bravo y por allí desfilaban legiones de economistas, sociólogos, antropólogos, cientistas políticos e historiadores. Uno de ellos fue Richard Morse. Yo leí su libro EI espejo de Próspero y escribí un artículo en portugués bastante influenciado por sus ideas: "Ariel, Calibán e Próspero: notas sobre a cultura latinoamericana", publicado en la revista Presença. Morse lo leyó y escribió algunas líneas elogiosas. Luego edité junto a Eduardo de León el libro titulado el Complejo de Próspero. Ensayos sobre cultura, modernidad y modernización en América Latina, y obtuve una beca Fulbright para realizar una pasantía de investigación en una universidad de Estados Unidos. Logré que Morse fuese mi anfitrión y él consiguió que la Oliveira Lima Library, parte de la Catholic University of America en Washington DC, me alojase. Fue mi primera experiencia profesional en Estados Unidos. En esos tres 
meses me dediqué a investigar las imágenes que los estadounidenses se habían formado de los latinoamericanos y ese fue el inicio de mi tercer libro: Muerte y resurrección de Facundo Quiroga. Una historia cultural de lo que ha significado ser moderno para los latinoamericanos.

Alli el contacto con Morse fue fluido, él era muy hospitalario y como su mujer se encontraba de viaje en Haití, en esos meses vivía solo; por esas razones había hecho de su casa de la calle Volta Place un lugar frecuente de encuentros. Una noche fuimos invitados a una pequeña reunión en las afueras de la ciudad y Morse nos llevó en su auto a mí y una historiadora brasileña. En el camino paramos a comprar una botella de un galón de vodka en un supermercado porque él solamente tomaba esta bebida, sola y con hielo. La reunión terminó cuando los cuatro litros de aguardiente se habían evaporado. Ya afuera Morse me lanzó las llaves por encima del techo del auto desde la puerta del acompañante, se subió, reclinó el asiento casi horizontalmente y me dijo: "drive me home"; cuando quise explicarle que yo tampoco estaba muy lúcido él ya estaba roncando. Las autopistas de las afueras de Washington a la una de la mañana son engorrosas para cualquiera, mucho más para un novato en la ciudad con algunos decilitros de vodka en la sangre. Estuve girando y girando por los accesos cerca de una hora buscando la salida correcta mientras Morse dormía a mi lado. Como no lo logré paré el auto al costado de la ruta, ya eran casi las dos de la mañana y yo estaba derrotado. Un rato después Morse se despertó, le expliqué la situación, intercambiamos lugares en el auto y despacito él manejó hasta su casa. Esa noche me quedé a dormir en el cuarto de huéspedes. Al día siguiente, mientras desayunábamos café negro, en el diario Washington Post había salido impresa una foto de media página del presidente de Brasil, Itamar Franco, sentado junto a la modelo Lilian Ramos en un palco del sambódromo. Ella no tenía ropa interior ("calcinha") y exhibía su sexo y su vello púbico a los fotógrafos, el presidente sonreía sin saber nada de lo que ocurría, como el bufón de corte. Morse no podía parar de reír, yo no podía parar de reír y la chica que había llegado esa mañana no podía parar de reír.

Después de mi estadía en Washington no volví a ver a Morse y murió pocos años después. De él recuerdo tres cosas que estructuran mi trabajo hasta el día de hoy: la primera es la importancia de sacar a Latinoamérica del lugar del enfermo, del incapaz, del subdesarrollado en que la ubicó el conquistador ibérico y luego el imperialismo europeo y estadounidense. En un mismo movimiento intelectual debemos salir del lugar del colonizado 
que admira a su colonizador perpetuando la subordinación y formular la crítica de las sociedades que se presentan como modelos a imitar. Es preciso construir el espacio de reconocimiento doble que implica una mirada crítica y atenta de injusticias y problemas, tanto como la afirmación de virtudes y logros, en América Latina y en el norte. El segundo aspecto que rescato a través del ejemplo de Morse, pero que por supuesto se nutre también de muchísimas otras influencias, fue la interdisciplinariedad como estrategia profesional y el ensayo como forma de escritura. ¿Por qué ceñirse a las fuentes exclusivas y a la mirada única de apenas una disciplina para entender un problema cultural, social, político? Si el mundo es diverso y multidimensional por qué no incluir en nuestra caja de herramientas diferentes llaves, tenazas y destornilladores. El tercer reconocimiento que me dejó mi primera estadía profesional en el norte y específicamente el intercambio profesional y personal con Morse fue el sentido del humor. Ojalá nunca olvide la capacidad crítica del humor.

Creo que fue por este período de tiempo que mi deseo apurado y adolescente de cambiar las injusticias del mundo cedió al peso de la humildad de la ignorancia; aquel enojo ante la terquedad de los hechos y la frustración de las continuidades fue mutando hacia la búsqueda de los espacios de libertad y resistencia a la prepotencia y las veleidades de la mirada del mundo rico y consumista que amenazan la propia supervivencia del mundo todo.

\section{5. ¿CÓMO DAR CLASE EL DÍA DESPUÉS?}

Obtuve mi doctorado en 1999 y al año siguiente nos trasladamos a la ciudad de Atlanta en Georgia, Estados Unidos. Mi esposa fue admitida para un doctorado en el Georgia Institute of Technology de esa ciudad y decidimos aceptar el desafío. Yo ya tenía un puesto efectivo en la Universidad de la República así que solicité licencia sin goce de sueldo. Estuve seis meses enviando cartas a posiciones laborales que se abrian en Atlanta $y$, una tras otra, las respuestas eran siempre negativas. Los recursos ahorrados se agotaban y el costo de vida se hacía cada vez más alto.

Mis hijos asistieron a escuelas públicas; la menor llegó con dos años, comenzó en una institución en la que era la única alumna de piel blanca y cabello rubio y además no sabía una gota de inglés. Al cabo de un tiempo no usó más el español, y hablaba un inglés muy particular con acento sureño y afroamericano. Ella descubrió la distinción racial dos años más 
tarde cuando un compañero de clase le dijo: "tú no sabés bailar esta música, solamente los negros pueden bailar bien el funk". Ese día nos preguntó por las diferencias de color de piel. Mi hijo mayor llegó con diez años de edad y también fue a una escuela pública en la que en su clase era el único blanco, pero en este caso el maestro era también blanco y canadiense. Aunque él ya sabía inglés, la experiencia que vivió no le gustó y se le hizo más complicado integrarse, además estaba previsto que al cabo de medio año regresara a Uruguay. Estas experiencias de vida se trasladaron a algunas de mis preocupaciones de trabajo pocos años después cuando abordé el tema del racismo en América Latina.

Luego de un largo período de seis meses finalmente me ofrecieron un puesto de Profesor Asistente en el School of History, Technology and Society de Georgia Tech. Me redactaron un contrato por un año académico, me ubicaron en la mejor oficina del departamento porque justo ésa quedaba libre ya que su ocupante era un historiador que se iba de sabático y me pedian que dictara en inglés cuatro cursos. Sería mi primera experiencia docente en el extranjero y naturalmente estaba feliz. Volví a ser contratado al año siguiente y hasta el día de hoy mantengo un contacto anual y regular con uno de los profesores del School of International Affairs que conoci entonces; hoy somos grandes amigos y en 2014 escribimos un libro juntos: Lessons from Latin America. Innovations in Politics, Culture and Development.

La docencia en Estados Unidos y en inglés fue todo un reto y un aprendizaje. El primer gran problema que debía enfrentar era la heterogeneidad de los estudiantes de licenciatura. A diferencia de los cursos en Uruguay y en casi toda América Latina, que hasta hace poco eran obligatorios y referidos a una sola disciplina, los de Estados Unidos son optativos y se ofrecen para muchas licenciaturas. Por esto tenía estudiantes que se estaban formando para ser arquitectos, ingenieros, técnicos en ciencias de la computación, oficiales de las fuerzas armadas o para otras profesiones. ¿Cómo haría para adaptar mi lenguaje de sociólogo, que usaba en mis clases para estudiantes de sociólogos, a un grupo tan heterogéneo con intereses tan diversos? Fue una de las experiencias más gratificantes de mi carrera docente. Tuve que depurar mi jerga especializada para volverla comprensible a todos y ese ejercicio es un potente clarificador de ideas. A partir de esa práctica, hasta el día de hoy molesto a mis estudiantes solicitándoles que me expliquen su idea de trabajo como si se la estuvieran contando a su abuela. Otra situación 
novedosa era el tipo de alumnos que asistían y la relación entre ellos con el profesor. Un día apareció por mi clase un muchacho altísimo de más de dos metros, afroamericano, con gorro de visera invertido, pantalones anchísimos bajos hasta la mitad de los glúteos, contornándose como si bailara a cada paso; se sentó al fondo junto a la ventana, desplegó un diario de deportes y desapareció detrás de sus páginas. Era una estrella del equipo de basketball de la universidad, en breve ganaría millones de dólares, se creía Apolo en la tierra pero para continuar en el equipo debía tomar algún curso. ¿Cuál actitud debía adoptar yo como profesor en semejante situación?

Recuerdo particularmente los mediodías, el momento antes del almuerzo. A las 11 y 55 generalmente terminaban todos los cursos de la mañana y la calle central de la universidad se llenaba de estudiantes y profesores rumbo al comedor. Era el mundo entero en dos cuadras. Lenguajes diferentes, colores de piel de todas las tonalidades, etnicidades múltiples, vestimentas africanas, indias, occidentales, olores salteados y un bullicio de feria. La diversidad cultural de las universidades estadounidenses es uno de sus fuertes. La multiculturalidad estimula la creatividad, amplía la libertad de opciones y nos abre la cabeza. Pero también genera miedos, recelos y reacciones violentas, como los asesinatos recurrentes de los estudiantes enloquecidos y aislados. He dedicado los últimos años de investigación a este tema (Arocena, 2012).

Otro desafío se me planteó el 12 de septiembre de 2001. Yo estaba trabajando en mi oficina cuando me comunicaron de las explosiones el día anterior. Las clases no se suspendieron el día después y se me planteó la incertidumbre de si dar clase regularmente o dedicarla a conversar sobre la tragedia de Manhattan. La mayoría de los profesores optaron por lo primero, yo, con la excusa que enseñaba sociología opté por lo último y fue un momento realmente tan duro como emocionante. ¿Cómo dar clase en un país que entró en guerra y fue atacado el día anterior?

Grosso modo el sistema universitario estadounidense ofrece una formación de licenciatura básica que evalúo un poco más superficial que la de las universidades decentes latinoamericanas. Luego es en el nivel de posgrados y especialmente de doctorados donde se produce el gran salto. Es en los posgrados donde se distancian del resto del mundo gracias a un sistema de apoyos económicos y a la integración de los cursos junto a la investigación conjunta con los profesores. ¿Cómo es posible competir con universidades que tienen más de veinte mil millones de dólares de capital? 
En las universidades latinoamericanas encontrar un investigador que se haya especializado en algún tema exterior a su país es como encontrar una aguja en un pajar. Las investigaciones que suelen realizar los sociólogos en América Latina están casi todas enfocadas hacia problemas nacionales o a lo sumo regionales, pero no salimos de la región. Por ejemplo, el año pasado hice un relevamiento de cuántos latinoamericanos dedicaron tiempo de investigación a estudiar la India y publicaron algún libro sobre temas de cultura, sociedad y política de ese país, ¿qué latinoamericano escribió desde la academia sobre la política y la cultura de la India, la mayor democracia del mundo con mil trescientos millones de habitantes? Nadie. Solamente el mexicano Octavio Paz lo hizo porque fue embajador allí. Esa es otra gran diferencia, en Estados Unidos se estudia el mundo entero y además hay investigadores del mundo entero trabajando allí. Tal vez éste sea el mayor aprendizaje de mi experiencia profesional en Estados Unidos, en Latinoamérica estudiamos poco el resto del mundo. En un planeta globalizado precisaríamos formar norteamericanistas, especialistas en Estados Unidos, sería necesario entender la India, nos va la vida en interpretar China. Hice un breve análisis de las investigaciones financiadas por la Universidad de la República en Uruguay y detecté que casi no existen investigaciones fuera de la región y la abrumadora mayoría están referidas a problemas locales. No tenemos en Uruguay cátedras sobre Rusia, ni sobre China ni sobre Oceanía, apenas una creada recientemente sobre medio oriente en la Universidad Católica del Uruguay.

He trabajado y vivido varios años en países del mundo más rico. Tuve la suerte de haber trabajado como profesor o investigador en varias universidades estadounidenses de gran nivel, así como en Canadá y en países europeos. Pude quedarme en más de una ocasión y establecerme fuera de mi país. De todas y en cada una de ellas me nutrí y crecí profesionalmente. En varios momentos dudé si volver al Uruguay pero siempre regreso.

\section{LA MIRADA DE HISASHI}

Escribí este artículo en Constanza, una pequeña ciudad alemana a orillas del lago homónimo en la frontera con Suiza. En la Universidad de Constanza están los Archivos Alfred Schutz, desde donde me cursaron la invitación para realizar una pasantía de investigación de tres semanas. Es un lugar ideal para escribir porque se está fuera de las demandas cotidianas que nos acechan en nuestros propios lugares de trabajo. Allí 
conocí un grupo extraordinario de gente y a un sociólogo japonés de la Universidad de Waseda. Me contó que tenía entre sus planes futuros mudarse fuera de Tokio a una zona rural ("on the countryside", fueron sus palabras exactas). Le dije que justamente hacía tres años yo había comprado seis hectáreas de campo en Uruguay en la Sierra de Carapé y construido una sencilla cabaña de madera sin luz ni agua de red al estilo de la que Thoreau describe en su Walden. Me miró y comenzó a reírse con cara de picardía, como si no me creyera. Él casualmente había estado en la cabaña de Thoreau porque vivió años en Boston, muy cerca del lago Walden. Le pregunté porque se reía. Se percató de que yo no estaba bromeando, abrió sus ojos como dos lunas llenas y me dijo: "entonces eres un príncipe". Su idea de mudarse al campo era algo asi como establecerse en una pequeña casa en un terreno de unos cientos de metros cuadrados en el medio de algún pueblito. No podía creer que alguien tuviese la posibilidad de comprarse semejante extensión de tierra vacía de seis hectáreas en el medio de un país fértil. Cada vez que me encuentro con la mirada del mundo rico relativizo los estereotipados fracasos de América del Sur y pongo entre paréntesis los tristes éxitos de quienes se auto ubicaron en el centro del mundo. Debe ser ésa, parte de la razón por la que siempre retorno.

Esta brevísima autobiografía o autoficción intelectual trata de idas y vueltas, de salidas y retornos, y de algunas de las influencias que percibo fueron significativas en mi vida, en mi formación profesional y en mi mirada sobre América del Sur. He vivido y trabajado muchos años fuera de mi país y en todo este tiempo intercalado las perspectivas cambian, se contradicen, algunas adquieren más fuerza y después se desinflan, y unas pocas, como flores que no inclinan su tallo, se mantienen siempre vivas. Tengo la certeza que de no haber pasado por estas experiencias en el extranjero en primer lugar no sería sociólogo. Y en segundo lugar que no hubiera construido el lugar desde el cual escribo e investigo. ¿Cuál es ese lugar? Es uno de fronteras, es un lugar que reconstruyo constantemente y que busco que me permita pararme en el límite y mirar hacia un lado y hacia el otro, que me ayude a elaborar la crítica recíproca y una sociología de doble mano, e incluso a veces borrar el límite. Claro, a diferencia de las experiencias exitosas de los tres escritores latinoamericanos con que comencé esta líneas, mi andar es a los tropezones. 


\section{Bibliografía}

Arocena, F., 2012, La mayoría de las personas son otras personas. Un ensayo sobre multiculturalismo en Occidente, Editorial Estuario, Montevideo.

Arocena, F. y Bowman, K., 2014, Lessons from Latin America. Innovations in Politics, Culture, and Development, University of Toronto Press, Canadá.

Benjamin, W., 2006, The Writer of Modern Life: Essays on Charles Baudelaire, Harvard University Press.

Cardoso, F. H. y Faletto E., 1969, Dependencia y desarrollo en América Latina, Siglo XXI, México.

Conrad, J., 1989, The Mirror of the Sea $\in$ A Personal Record, The World Classics Oxford University Press.

Duarte, B. K., 2014, "Autofiction"; en Bernd, Z. y Dei Cas-Giraldi, N. (dir.), 2014, Glossaire des mobilités culturelles, P.I.E. Peter Lang, TransAtlántico Literaturas, Bruselas.

Germani, G., 1969, Sociología de la modernización: Estudios teóricos, metodológicos y aplicados a América Latina, Paidós, Buenos Aires.

Mills, C. W., 1959, The Sociological Imagination, Oxford University Press, Oxford.

Nisbet, R., 1977, La formación del pensamiento sociológico, Amorrortu editores, Buenos Aires.

Rudner, R., 1973, Filosofía de la ciencia social, Alianza Editorial SA, Madrid.

Schwartz, J. (ed.), 1991, Las vanguardias en América Latina, Cátedra, Madrid.

Wagner, R., 1981, The Invention of Culture, The University of Chicago Press, Chicago. 